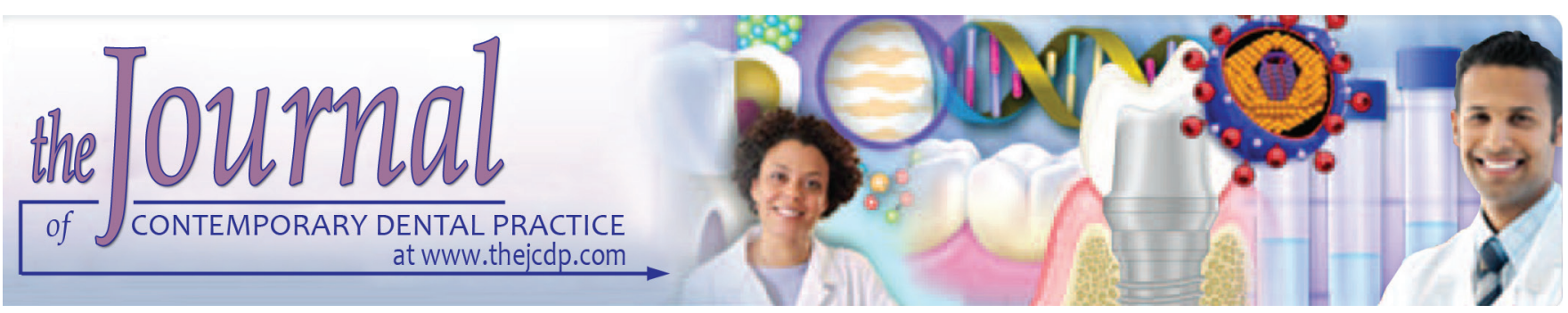

\title{
In vitro Comparison of Impact of Different Bleaching Agents on the Microhardness of Enamel
}

\author{
${ }^{1}$ Subhra Dey, ${ }^{2}$ Vinisha Pandey, ${ }^{3}$ Anuj Kumar, ${ }^{4}$ Neha Awasthi, ${ }^{5}$ Anshu Sahu, ${ }^{6}$ Sudarshan C Pujari
}

\begin{abstract}
Background: Various agents are used these days for increasing the esthetics. One such procedure is bleaching that offers various advantages, as it is minimal invasive and cheap option to color the teeth and remove stain. The altered enamel after the bleaching process shows surface demineralization and porosities. The present study aimed to evaluate the effect of different bleaching agents on the microhardness of enamel.

Materials and methods: A total of 100 freshly human extracted maxillary premolar teeth were selected for the study. Teeth with sound tooth structure were included for the study. All the specimens were randomly divided into four groups with 25 specimens in each group depending upon the type of bleaching agent used: Group A, artificial saliva (Control group); Group B, $35 \%$ hydrogen peroxide (HP); Group C, 25\% HP; Group D, 10\% carbamide peroxide (CP). Knoop Hardness Number (KHN) was calculated at 24, 48-hour, and 7-week interval.
\end{abstract}

Results: Results showed no statistical significant differences between the microhardness of enamel of different groups

\footnotetext{
${ }^{1}$ Department of Conservative Dentistry and Endodontics, Index Institute of Dental Sciences, Indore, Madhya Pradesh, India

${ }^{2}$ Department of Conservative Dentistry and Endodontics Faculty of Dental Sciences, Rama University, Kanpur, Uttar Pradesh, India

${ }^{3}$ Department of Oral and Maxillofacial Surgery, Bhagwan Mahavir Medical Superspeciality Hospital, Ranchi, Jharkhand India

${ }^{4}$ Department of Pedodontics and Preventive Dentistry, School of Dental Sciences, Sharda University, Greater Noida, Uttar Pradesh, India

${ }^{5}$ Department of Orthodontics and Dentofacial Orthopedics Hazaribag College of Dental Sciences and Hospital, Hazaribag Jharkhand, India

${ }^{6}$ Department of Conservative Dentistry and Endodontics, PDU Dental College, Solapur, Maharashtra, India

Corresponding Author: Subhra Dey, Senior Lecturer Department of Conservative Dentistry and Endodontics, Index Institute of Dental Sciences, Index City, Nemawar Road, Indore 452016, Madhya Pradesh, India, Phone: +919501544877 e-mail: subhrad@gmail.com
}

$(p<0.005)$. A slight fall in the value of KHN was seen in all the groups, except for the control group, although the results were statistically nonsignificant $(p>0.005)$.

Conclusion: Although nonsignificantly, all the bleaching solutions produced some amount of alterations in the microstructure of enamel. More studies with higher study groups and more advanced estimation technologies are required to minimize microstructure alterations and promote for better outcome of bleaching procedures.

Keywords: Bleaching, Enamel, Microhardness.

How to cite this article: Dey S, Pandey V, Kumar A, Awasthi N, Sahu A, Pujari SC. In vitro Comparison of Impact of Different Bleaching Agents on the Microhardness of Enamel. J Contemp Dent Pract 2016;17(3):258-262.

Source of support: Nil

Conflict of interest: None

\section{INTRODUCTION}

One of the most common problems with dental treatment (brackets) is demineralization and white spots especially when such lesions have the potential to turn into carious lesions under poor oral hygiene conditions. Literature quotes numerous studies that report demineralization of enamel under such environment. ${ }^{1-3}$ One way of controlling such lesions to occur is by increasing the enamel resistance especially in those areas. ${ }^{4}$ Various agents are used these days for increasing the esthetics. One such procedure is bleaching that offers various advantages, as it is a minimal invasive and cheap option to color the teeth and remove stains. ${ }^{5}$ Since, ninetieth century, peroxide use for tooth bleaching purpose has been reported, which showed that it has the capacity to change tooth's color. ${ }^{6}$

The altered enamel after the bleaching process, when observed under scanning electron microscope, shows surface demineralization, and porosities. At the same time, studies with contrasting results have also been quoted in the past that report negligible changes in chemical and physical properties of the bleached enamel 
surface. As far as microhardness (MH) is concerned, the results are very controversial in different studies probably due to difference in methods adopted..$^{7-10}$ Hydrogen peroxide (HP) decomposes into oxygen and per hydroxyl free radical resulting in initiation of redox reaction that causes of bleaching of the teeth. ${ }^{11,12}$ Because of their electron-deficient state, these free radicals diffuse into organic matrix of the pigments by penetrating the enamel and dentin and become stable. ${ }^{11,13}$ After this, there is transformation of unsaturated organic molecules into smaller components and it is a very nonspecific reaction and the bleaching agents alter the components of enamel and dentin and structural changes occur in them. ${ }^{14}$

Effect of bleaching agents has also been studied in the past. One of such study showed that it resulted in surface degradation and softening of composite resin on 5-day treatment with bleaching agents. In another study by Cehreli et al, they concluded that the effect of bleaching gels was dependent on the materials. ${ }^{15,16}$ Therefore, we evaluated the effect of different bleaching agents on the $\mathrm{MH}$ of enamel.

\section{MATERIALS AND METHODS}

A total of 100 freshly human extracted maxillary premolar teeth were selected for the study. Teeth with sound tooth structure were included for the study. Extracted teeth were washed and cleaned with saline and were stored in $0.1 \%$ thymol solution at neutral $\mathrm{pH}$ at $5^{\circ} \mathrm{C}$. All the teeth were sectioned at the cementoenamel junction using low speed disk separating the specimen into crown and root. The crowns of the specimens were further sectioned to obtain 100 slabs that were embedded one by one in acrylic resin cylinders. The buccal surfaces of the slabs were grounded into flat surface with the carborundum disk and then polished with carborundum paper. The final made specimens were then stored in pure distilled water until further use to avoid dehydration.

Microhardness of the specimens without solution treatment was calculated with FM-810 (Future Tech, Japan) and Knoop Hardness Number (KHN) was calculated (Figs 1A to E).

All the specimens were randomly divided into four groups with 25 specimens in each group depending upon the type of bleaching agent used.

- Group A, artificial saliva (Control group),

- Group B, 35\% HP,

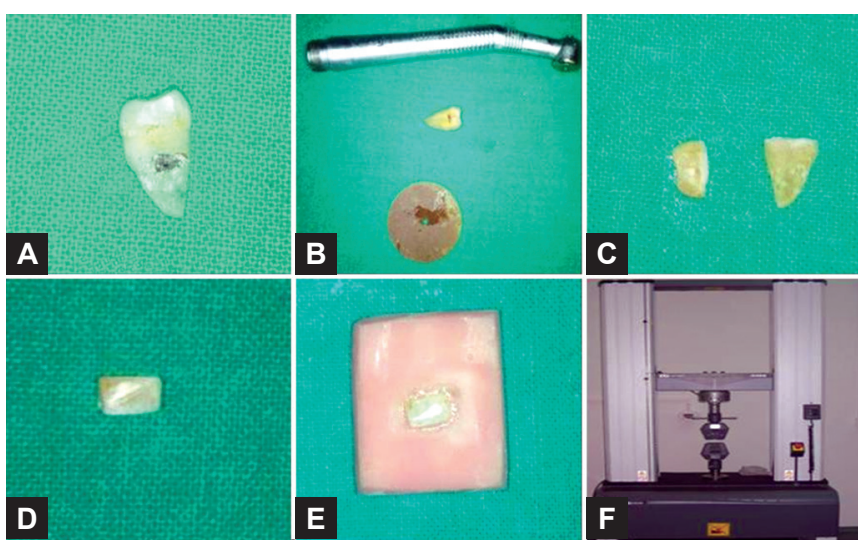

Figs 1A to E: (A) Maxillary premolar; (B) Armamentarium; (C) Sectioned tooth at cervicoenamel junction; (D) Crown part of tooth sectioned in rectangular slab; (E) Rectangular slab embedded in acrylic resin cylinder; and (F) Sample subjected to Universal Testing Machine for estimation of microhardness

- Group C, 25\% HP,

- Group D, 10\% carbamide peroxide (CP).

The technique of bleaching by Rodrigues et $\mathrm{al}^{17}$ was followed on the specimens and $\mathrm{KHN}$ was calculated at 24, 48-hour, and 7-week interval. The bleaching agents were mixed and used according to the instructions given by the manufacturer. Application of approximately $1 \mathrm{~mm}$ coating of the bleaching gel was done on the test group specimens. Before the starting of the second bleaching cycle, the specimens were cleaned with distilled water and then dried. The artificial saliva used was composed of calcium nitrate solution, water molecules, sodium hypophosphate solution, potassium chloride, Tris(hydroxymethyl)aminomethane, and fluoride solution. ${ }^{18}$

All these results were calculated with Statistical Package for the Social Sciences (SPSS) software. One-way analysis of variance (ANOVA) was used to assess the level of significance and p-value of less than 0.05 was considered as significant.

\section{RESULTS}

Our results showed no statistical significant differences between the $\mathrm{MH}$ of enamel of different groups $(\mathrm{p}<0.05)$ (Table 1). A slight fall in the value of KHN was seen in all the groups, except for the control group, although the results were statistically nonsignificant $(\mathrm{p}>0.05)$.

After 24 hours of bleaching, the $\mathrm{MH}$ of all the specimens declined significantly in all the groups, although no significant results were seen in between the

Table 1: Knoop hardness number values of different groups at 24, 48 hours, and 7-week interval

\begin{tabular}{llllll}
\hline Groups & 0 hr (untreated) & 24 hours & 48 hours & 1 week & $p$-value \\
\hline A; Control & $312 \pm 15.25$ & $335 \pm 18.28$ & $330 \pm 12.22$ & $325 \pm 16.40$ & 0.213 NS \\
B; $35 \%$ HP & $311 \pm 16.45$ & $300 \pm 12.22$ & $308 \pm 13.31$ & $310 \pm 16.25$ & 0.322 NS \\
C; $25 \%$ HP & $312 \pm 14.40$ & $305 \pm 17.30$ & $302 \pm 11.25$ & $309 \pm 12.22$ & 0.456 NS \\
D; $10 \%$ CP & $313 \pm 15.10$ & $307 \pm 14.18$ & $309 \pm 19.25$ & $310 \pm 13.25$ & 0.012 NS \\
\hline
\end{tabular}

NS: Nonsignificant 


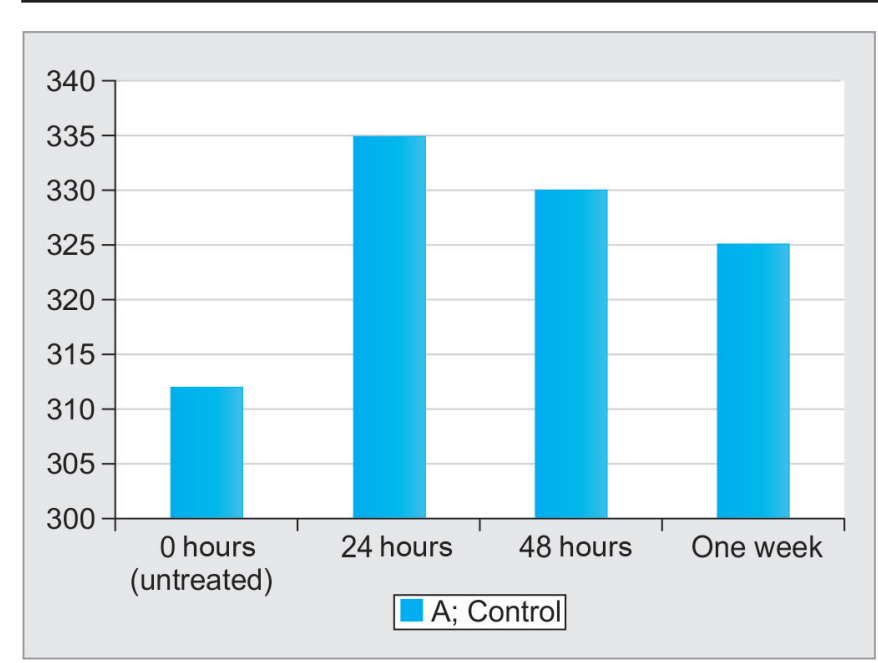

Graph 1: Mean KHN values of control group (A) at 24, 48 hours, and 7-week interval

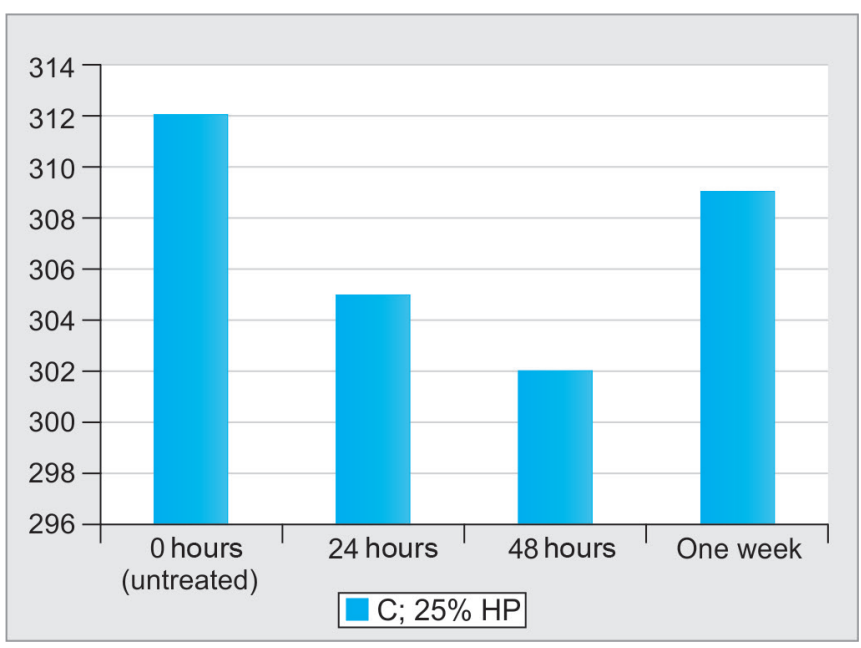

Graph 3: Mean $\mathrm{KHN}$ values of group C containing $25 \% \mathrm{HP}$ at 24,48 hours, and 7-week interval

different test groups. However, on further evaluation at 48-hour and 1-week duration, the results were varying with nonsignificant values (Graphs 1 to 4 ).

\section{DISCUSSION}

Ever since the introduction of bleaching techniques using $\mathrm{HP}$ and $\mathrm{CP}$, different studies have been carried out to assess the effect of these chemical agents on the microstructure of the tooth component. ${ }^{19-21}$ Bleaching procedures also involve different techniques with different composition of peroxides. These concentrations can be as high as 35 to $37 \%$ of peroxides. ${ }^{22}$ Literature quotes numerous studies showing adverse effects of these agents on tooth microstructures. ${ }^{23,24}$

Hence, we evaluated the effect of various solutions used in bleaching process on enamel microstructures.

Our study group included 100 enamel slabs that were exposed to different bleaching agents followed by

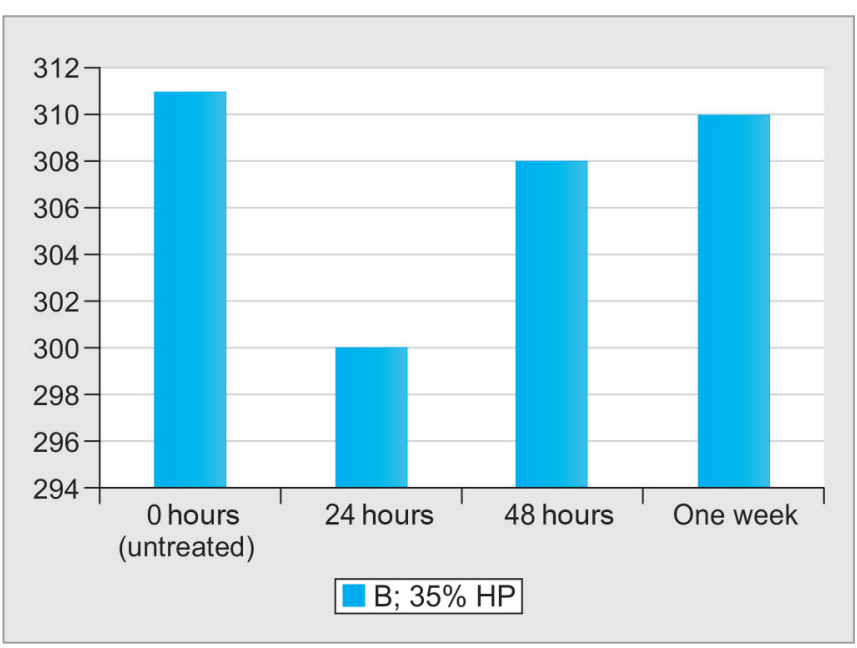

Graph 2: Mean KHN values of group B containing $35 \% \mathrm{HP}$ at 24,48 hours, and 7-week interval

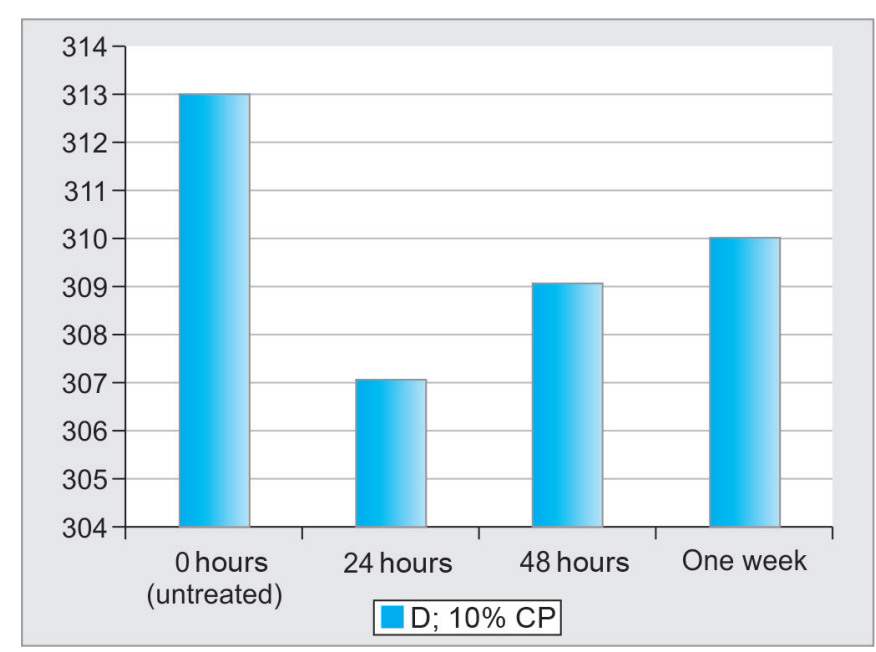

Graph 4: Mean KHN values of group D containing $10 \% \mathrm{CP}$ at 24, 48 hours, and 7-week interval

evaluation of $\mathrm{MH}$ after 24, 48 hours, and 1-week time. Although alterations were seen in the study group, no statistically significant results were seen. In the study group containing $35 \% \mathrm{HP}$, the $\mathrm{MH}$ declined initially from 311 to $300 \mathrm{KHN}$ followed by slowly increasing to value of 310 (Table 1). Similarly, in other group containing CP, the $\mathrm{MH}$ initially shows a downfall followed by a rise to a value of $310 \mathrm{KNH}$ at 7 days' time.

These findings were in accordance with the results obtained by different studies who noticed no enamel alteration after bleaching solution exposure. . $^{25,26}$

Rodrigues et $\mathrm{a}^{14}$ evaluated the effect of dental bleaching on dental enamel $\mathrm{MH}$ after the use of bleaching agents with and without carbopol as a thickener agent in bovine teeth and concluded that dental bleaching with $10 \% \mathrm{CP}$ and the treatment with $2 \%$ carbopol or carbowax for 6 hours daily did not statistically reduce enamel MH.

Although no statistical significant results are seen in the present study $(p>0.005)$, some alterations do occur in 
the microstructure of enamel after bleaching agents. Pizani et al, ${ }^{19}$ following their study on bleaching agents with and without calcium on enamel microstructure, showed that in association with higher concentration of $\mathrm{HP}$, calcium may decrease the $\mathrm{MH}$ and structural changes on enamel.

Calcium was introduced in the bleaching system to decrease and minimize the enamel structure alterations and loss of minerals. ${ }^{27,28}$ Results of the study by Mondelli et $\mathrm{al}^{29}$ on the effect of different bleaching agents on microstructure of enamel not only shows a fall in the initial values of hardness test but also shows a slow rise in the hardness values posttreatment contact with saliva. In 2004 , in a scanning electron microscopic study on enamel hardness following bleaching treatment, Pinto et $\mathrm{al}^{30}$ found that the initial KHN value was similar in all the groups, while later on, specimens submitted to all bleaching regimens showed a decrease in KHN. From the results, they concluded that some significant amount of microalterations do occur in enamel following treatment with different bleaching agents. ${ }^{30}$

The reduction in KHN following bleaching treatment can be controlled by the action of saliva or artificial demineralizing solutions. ${ }^{31}$ Although nonsignificant, we also observed some variation with passage of time in the MH of enamel.

\section{CONCLUSION}

From the study, it can be concluded that although nonsignificantly, all the bleaching solutions produced some amount of alterations in the microstructure of enamel. Furthermore, these alterations consistently declined with the passage of time. More studies with higher study groups and more advanced estimation technologies are required to minimize microstructure alterations and promote for better outcome of bleaching procedures.

\section{REFERENCES}

1. Gorelick L, Geiger AM, Gwinnett AJ. Incidence of white spot formation after bonding and banding. Am J Orthod 1982 Feb;81(2):93-98.

2. O'Reilly MM, Featherstone JD. Demineralization and remineralization around orthodontic appliances: an in vivo study. Am J Orthod Dentofacial Orthop 1987 Jul;92(1):33-40.

3. Mitchell L. Decalcification during orthodontic treatment with fixed appliances-an overview. Br J Orthod 1992 Aug;19(3):199-205.

4. Pol TR, Naik CR, Gupta R, Pol A, Sanghvi S. Incorporation of casein phosphopeptide-amorphous calcium phosphate into glass-ionomer cement for orthodontic band cementation-an in vitro study. Int J Stomatol Res 2013;2:5-10.

5. Markovic L, Jordan RA, Lakota N, Gaengler P. Micromorphology of enamel surface after vital tooth bleaching. J Endod 2007 May;33(5):607-610.

6. Borges A, Zanatta R, Barros A, Silva L, Pucci C, Torres C. Effect of hydrogen peroxide concentration on enamel color and microhardness. Oper Dent 2015 Jan-Feb;40(1): 96-101.

7. Attin T, Schmidlin PR, Wegehaupt F, Wiegand A. Influence of study design on the impact of bleaching agents on dental enamel microhardness: a review. Dent Mater 2009 Feb;25(2):143-157.

8. Joiner A. Review of the effects of peroxide on enamel and dentine properties. J Dent 2007 Dec;35(12):889-896.

9. Soldani P, Amaral CM, Rodrigues JA. Microhardness evaluation of in situ vital bleaching and thickening agents on human dental enamel. Int J Periodontics Restorative Dent 2010 Apr;30(2):203-211.

10. Akal N, Over H, Olmez A, Bodur H. Effects of carbamide peroxide containing bleaching agents on the morphology and subsurface hardness of enamel. J Clin Pediatr Dent 2001 Summer;25(4):293-296.

11. Goldstein RE, Garber DA. Complete dental bleaching. Chicago: Quintessence Books; 1995. p. 165

12. McCracken MS, Haywood VB. Demineralization effects of 10 percent carbamide peroxide. J Dent 1996 Nov;24(6):395-398.

13. Frysh H, Bowles WH, Baker F, Rivere-Hidalgo F, Guillen G. Effect of $\mathrm{pH}$ on hydrogen peroxide bleaching agents. J Esthet Dent 1995;7(3)130-133.

14. Rodrigues JA, Oliveira GPF, Amaral CM. Effect of thickener agents on dental enamel microhardness submitted to at-home bleaching. Braz Oral Res 2007 Apr-Jun;21(2):170-175.

15. Campos I, Briso AL, Pimenta LA, Ambrosano G. Effects of bleaching with carbamide peroxide gels on microhardness of restoration materials. J Esthet Restor Dent 2003;15(3):175-182.

16. Cehreli ZC, Yazici R, Garcia-Godoy F. Effect of home-use bleaching gels on fluoride releasing restorative materials. Oper Dent 2003 Sep-Oct;28(5):605-609.

17. Rodrigues JA, Basting RT, Serra MC, Rodrigues AL Jr. Effects of $10 \%$ carbamide peroxide bleaching on enamel microhardness at different bleaching times. Am J Dent 2001 Apr;14(2): 67-71.

18. Pinto CF, Paes Leme AF, Cavalli V, Giannini M. Effect of $10 \%$ carbamide peroxide bleaching on sound and artificial enamel carious lesions. Braz Dent J 2009;20(1):48-53.

19. Pizani AM, Tholt B, Paciornik S, Dias KRH, Albuquerque PPA, Queiroz CS. Dental bleaching agents with calcium and their effects on enamel microhardness and morphology. Braz J Oral Sci 2015;14(2)154-158.

20. Cavalli V, Giannini M, Carvalho RM. Effect of carbamide peroxide bleaching agents on tensile strength of human enamel. Dent Mater 2004 Oct;20(8):733-739.

21. Cavalli V, Reis AF, Giannini M, Ambrosano GMB. The effect of elapsed time following bleaching on enamel bond strength of resin composite. Oper Dent 2001 Nov-Dec;26(6):597-602.

22. Mokhlis GR, Matis BA, Cochran MA, Eckert GJ. A clinical evaluation of carbamide peroxide and hydrogen peroxide whitening agents during daytime use. J Am Dent Assoc 2000 Sep;131(9):1269-1277.

23. Akal N, Over H, Olmez A, Bodur H. Effects of carbamide peroxide containing bleaching agents on the morphology and subsurface hardness of enamel. J Clin Pediatr Dent 2001 Summer;25(4):293-296.

24. McGuckin RS, Babin JF, Meyer BJ. Alterations in human enamel surface morphology following vital bleaching. J Prosthet Dent 1992 Nov;68(5):754-760.

25. McCracken MS, Haywood VB. Effects of $10 \%$ carbamide peroxide on the subsurface hardness of enamel. Quintessence Int 1995;26(1)21-24. 
26. Smidt A, Weller D, Roman I, Gedalia I. Effect of bleaching agents on microhardness and surface morphology of tooth enamel. Am J Dent 1998;11(2):83-85.

27. Cavalli V, Arrais CA, Giannini M, Ambrosano GM. High-concentrated carbamide peroxide bleaching agents effects on enamel surface. J Oral Rehabil 2004 Feb;31(2):155-159.

28. Cochrane NJ, Cai F, Huq NL, Burrow MF, Reynolds EC. New approaches to enhanced remineralization of tooth enamel. J Dent Res 2010 Nov;89(11):1187-1197.

29. Mondelli RFL, Gabriel TRCG, Rizzante FAP, Magalhães AC, Bombonatti JFS, Ishikiriama SK. Do different bleaching protocols affect the enamel microhardness? Eur J Dent 2015 Jan-Mar;9(1):25-30.

30. Pinto CF, Oliveira RD, Cavalli V, Giannini M. Peroxide bleaching agent effects on enamel surface microhardness, roughness and morphology. Braz Oral Res 2004 Oct-Dec; 18(4):306-311.

31. Perdigão J, Francci C, Swift EJ Jr, Ambrose WW, Lopes M. Ultra-morphological study of the interaction of dental adhesives with carbamide peroxide-bleached enamel. Am J Dent 1998 Dec;11(6):291-301. 